\title{
GENERAL ANAESTHESIA FOR DENTAL SURGERY
}

\author{
By W. S. McConNell, M.B., B.S., D.A. \\ Anaesthetist Guy's Hospital and Dental School
}

While anaesthesia for dental surgery does not differ basically from that required for operations on other parts of the body, it makes wider demands on the active assistance of the anaesthetist and presents certain problems peculiar to the site of operation. The dental surgeon requires an anaesthetic which, though brief, must be tranquil and must ensure that the patient feels nothing of the extraction, and is fit enough to walk home afterwards. The anaesthetist must be prepared to fulfil these conditions whether it is for the removal of a deciduous tooth in a child, a broken-down lower molar in a resistant adult, or the last remaining incisor in an octogenarian. In addition, however satisfactory the anaesthesia the dental surgeon will not consider the result a success unless he receives the active co-operation of the anaesthetist. $\mathrm{He}$ must know how to assist by holding the head as in a vice when upper teeth are being extracted, at the same time guarding the lower lip from possible bruising by the forceps; how to keep out of the way when the dental surgeon encircles the patient's head with his left arm when removing a right lower molar, or how to give access to the tooth in a patient with trismus.

Although called in to give a 'gas,' the anaesthesia must be selected for the type of patient. The increasing number of drugs available (such as divinyl ether, trichlorethylene and cyclopropane) used alone or as adjuvants to nitrous oxide have tended to make apparatus more complicated. While this is no drawback in hospital work where a Walton or McKesson apparatus may be found, it is a handicap on a simple portable machine such as the Macintosh Bag. ${ }^{1}$ The three cardinal advantages of such a simple apparatus are that the whole attention may be given to the patient and not distracted by the necessity to make minute adjustments or observations, that it can be opened ready for use in ro seconds, and that no part is so delicate that rough handling in and out of a car leads to leaks or damage. The writer carries two Macintosh Bags, each of which contains nitrous oxide apparatus, tubes of ethyl chloride, ampules of 'Vinesthene' and an Oxford Inhaler, a ro cc. syringe with needles and ampoules of thiopentone as well as mouth-props, throat packs, Mason's gags, tongue forceps and a strap.

\section{The Adult in the Chair-Preparation}

For the adult, nitrous oxide and oxygen remains the-anaesthetic of choice for short procedures in normal patients. It is considered unwise to expose a patient for longer than ro minutes to the degree of oxygen lack involved in nitrous oxide anaesthesia obtained without the help of heavy sedation. If the patient is not in robust health (either from age or disease) the dangers of a shorter period of anoxaemia are much increased.

Before entering the surgery the patient should have been asked to empty the bladder. The responsibility for this small request is sometimes left to a door-maid or hospital porter. It is likely to be omitted when the dental surgeon is preoccupied with other details of a patient of high social position or from lack of thought if the patient happens to be a colleague. It is particularly important in the case of women and children; many of the former suffer from some degree of stress-incontinence, and the latter's control of the bladder may be poor.

As the patient enters the room, and while being made comfortable in the chair the anaesthetist forms an opinion of the patient's state of health. The inspection includes body configuration (Asthenic or Plethoric type), whether the patient is breathless or has a cough, the presence of pallor or cyanosis with possible clubbing of the fingers or swelling of the ankles, and evidence of loss of weight. The apparent age is compared with possible information. If observation raises a doubt about the physical condition, the patient is questioned concerning any illness which has kept him in bed for 28 days.

A man should be asked to remove his collar for comfort if it appears tight, or if the number of extractions suggests that there may be inadvertent soiling with blood. For the latter reason a woman is advised to remove a pearl necklace.

After the writer had dislodged a loose front tooth during the insertion of a throat-pack, the value of a quick inspection of the mouth was realized. The position of standing teeth is visualized in relation to the insertion of a prop or the possible use of a Mason's gag, and presence of porcelain jacket crowns, gold bridges or loose teeth noted.

A glance at the teeth to be extracted may give the 
anaesthetist an idea of the probable duration of anaesthesia, and he will know where to stand and how he can be of the maximum assistance to the dental surgeon in holding the head or supporting the jaw.

The feet may rest anywhere as long as they cannot obtain a purchase against the foot rest, the wall of the room or are within striking distance of surgery equipment. The writer has had the misfortune to see two chairs broken by patients who have straightened their backs while their feet were supported against the foot-rest and their shoulders under the old type of head-rest. In one surgery where the chair was too near the wall a patient gave a sharp push with his foot and tipped the heavy chair over backwards. In yet another case a patient brought his foot down on the instrument tray of a sterilizer; the splashing of the boiling water was a sharp reminder of the medico-legal responsibilities in the care of the unconscious patient.

The back is applied firmly to the back-rest of the chair by asking the patient ' to make himself as tall as possible.' The head-rest is then adjusted to support the neck. If used as a head-rest and not a neck-rest, the slightest downward slide o i the patient will result in a ' chin on the chest' position in which the removal of upper teeth may be impossible. The anaesthetist should have no hesitation in adjusting the position of the head-rest during the progress of the extractions ; should the patient slide, a satisfactory head position can be maintained by following the movement of the head with the head-rest.

If the extraction of the teeth is expected to be difficult, or experience suggests that the patient may be restless, the use of a strap to maintain a good position in the chair is of much help. The combined efforts of the dental surgeon and anaesthetist without additional help cannot replace a muscular patient who assumes a bad position in the chair. The movement which completely defeats the anaesthetist is that of crossing one leg over the other, and then twisting and sliding down the chair sideways ; the patient's head then ends up halfway down the back of the chair in a position in which the maintenance of anaesthesia and the extraction of teeth are impossible. The strap is passed over the upper part of the thighs and below the back and seat of the chair with the object of maintaining the pelvis in contact with the back of the chair. It need not be tightened unless required, and never until the patient has lost consciousness. An incorrectly placed strap around the patient's chest or abdomen will only hold him in the faulty position into which he may slip.

It is of great help to the anaesthetist if a dental prop is inserted before the start of the induction. The stimulus of $r$ pe zing the mouth at a later stage upsets the smoothness of the anaesthesia and may lead to mouth breathing and reflex movements. As the prop is placed in position the use of the word 'bite' is avoided, as it suggests closing the mouth. The writer uses the Truby type, with a choice of five sizes. The De Pass folded rubber block has an advantage over the fixed height of the Truby in that if the mouth is opened more widely during the course of the extractions it does not slip ; many patients, however, find it uncomfortable to have their mouth so 'sprung open.' If possible the prop should be so placed that the use of a Mason's gag is avoided. Thus if premolar teeth on both sides of the mouth have to be extracted it is an advantage to have a small prop far back. The dental surgeon is then asked to remove the tooth on the same side as the prop first, so that even if it should slip forward a little during the movements of the extraction, it will still allow access to the tooth on the other side without a ' change.'

\section{The Induction}

As little time as possible should elapse between the insertion of the prop and the presentation of the nose-piece $\frac{1}{2}$ an inch away from the patient's nose. Nitrous oxide is blown from this distance until it is thought that the state of analgesia is reached, after which the nose-piece is allowed to come in contact with the face. Although this method prolongs the induction, it avoids any resis- 6 tance to expiration with the subjective sensation? of being ' blown up.'

The one reliable sign of anaesthesia is nasal automatic respiration, and until this is established, the patient should not be considered ready for the extraction. Should the patient revert to mouth breathing in the early stages of induction, the effect of persuasion, reinforced by the feel of a lightly applied hand over the mouth should be tried. If this fails to restore nasal breathing, a mouth-cover with a supply of nitrous oxide becomes essential. Attempts to restore nasal breathing by increasing the pressure of the gas by closure of the expiratory valve and pressure on the resevoir bag are usually unsuccessful.

While it is legitimate to ask a patient to breathe through the nose, other instructions about the type of respiration should be avoided, for it confuses him to think about what is normally an unconscious act.

A heavily applied hand occluding the mouth in a patient who persists in mouth-breathing will not only produce a feeling of considerable discomfort, but may be dangerous. The writer in his inexperience has applied a hand so firmly to exclude mouthbreathing that the patient was carried to the point of respiratory arrest from suffocation, and whose condition demanded artificial respiration 
The patient is encouraged to relax by asking him to ' drop his shoulders.' This request (advised by Macintosh $^{2}$ ) can be understood and obeyed, and the relaxation of tension can be seen immediately.

The usual type of nose-piece has an expiratory valve from which any change in the sound of the patient's respiratory rhythm can readily be heard. If oxygen is not added to nitrous oxide when automatic respiration is obtained, the level of anaesthesia will deepen, a stage which can be recognized by the sound of a snore or a catch in inspiration. (The catch in inspiration is not an infallible sign of deep nitrous oxide anaesthesia : the writer has met the patient who volunteered the information that in his particular case it occurs early in the induction, and as a result of previous anaesthetists relying on it as a sign, he had always felt the extractions.) By allowing the oxygen lack to continue still further the respirations will be heard to become more rapid, and lose their smooth rhythm. They sound snatching, irregular, and finally become slyort and sobbing.

A throat pack of suitable size is inserted when well-established nasal automatic breathing is present. While in some cases a throat pack inserted before satisfactory anaesthesia is present does assist in maintaining nasal breathing, in others it will induce gagging with resultant slipping of the prop. All types of throat-pack, whether made from a marine sponge, gauze squares or pad of cotton-wool should have a tape or cord firmly attached. The writer has removed a small slimy mass from the glottic opening with Magill's forceps : at the start of the extractions it was a 6 in. square of gauze without a tape.

To appreciate how much his co-operation assists the dental surgeon, the anaesthetist should have personal experience of extracting teeth under nasal nitrous oxide anaesthesia. When upper front teeth are being removed, the temporary lifting of the nose-piece allows the first finger of the dental surgeon's left hand to displace the upper lip from the tooth. The anaesthetist meanwhile rests a finger in the sulcus of the lower jaw and so protects the lower lip from possible bruising by the forceps. The head should be held as in a vice when upper molars are being extracted, and by applying counter pressure with his shoulder on the patient's head, the anaesthetist counteracts the upward thrust of the forceps. When upper wisdom teeth are to be removed, pushing the mandible to the same side as the affected tooth displaces the coronoid process, and gives the dental surgeon greater access. During the extraction of lower molars the fingers of both hands should support the mandible. When both hands are thus occupied, the use of a metal nose-piece with a poor gastight joint enables the anaesthetist to give added air by displacing it forwards from the nose with his two thumbs. This method of adding air is also useful when holding a Mason's gag against the cheek with one hand and supporting the jaw for the extraction of a tooth on the other side. When lower right molars are being removed, the anaesthetist should be prepared to move well over to the left of the chair to allow the left arm of the extractor to encircle the patient's head, to support the jaw with both hands and to tilt the whole head over to the right side.

When a change from one side of the mouth to the other is necessary it is often possible to insert a second dental prop rather than use a mouth gag. A carelessly inserted Mason's gag may pinch the lip, tear the mucous membrane if it slips into the sulcus, loosen a deciduous tooth or dislodge a filling in a molar.

The anaesthetist selects a slightly smaller prop than the one already in the mouth, and using the finger and thumb of one hand in the sulcus, opens. the mouth a little wider, and places the second prop. in position. If the dental surgeon is asked to put in the second prop, the mouth is more readily opened by the anaesthetist depressing the tip of the jaw with the ball of the left thumb, while his. right hand, firmly applied to the patient's forehead prevents any depression of the whole head. The manipulations involved in changing a prop are made easier by the addition of a breath of air or oxygen : this will diminish any increased tone in the masseter muscles due to anoxia.

To allow the dental surgeon access to a lower molar in a patient with trismus whose mouth will only open $\frac{1}{4}$ of an inch, a small 'baby' prop is. inserted on one or other side before the induction. When established nasal automatic breathing obtains, a Mason's gag is introduced with the blades resting well back on molar teeth and the mouth opened a fraction. The 'baby' prop will then drop out, and a second Mason's gag is inserted in its place. With a gag in each hand the anaesthetist then exerts even pressure on both sides of the mandible and the mouth is slowly opened. When sufficient room has been obtained the gag on the side of the affected tooth is removed, the throat pack is inserted, and the dental surgeon invited to start.

\section{Recovery}

During the recovery period the patient is allowed to regain consciousness with the throatpack and prop still in position, and with no. additional stimulus other than the spoken word. He should be told where he is, and that the teeth are out, the hand of the anaesthetist meanwhile shades the eyes from the confusing effect of bright lights. Control of the patient's head should not be 
relinquished until full consciousness has returned. While away washing his hands, the writer has had the misfortune to turn round and watch a patient rise suddenly from the chair, fall forward, and strike his head on a stone floor.

\section{The Difficult Adult}

Among the types of patient who would be classed as ' normal' and given nasal nitrous oxide is what might be termed 'The Ageing Athlete.' $\mathrm{He}$ is a well-built man in the late fifties or early sixties who lives well, and who in youth played rugger or rowed for his college but now takes no exercise. If such a patient is not to feel the extractions or make a reflex response to the painful stimulus, a considerable element of anoxia must be present in the nitrous oxide anaesthesia. The effect of the oxygen lack on a possibly poor heart muscle is shown in the signs of circulatory distress, which if allowed to persist are dangerous. It is unfortunate that such patients often have difficult teeth to extract: the anaesthetist should have no hesitation in advising abandonment of the uncompleted extractions and a change to a less harmful anaesthetic on another occasion. Pallor (sometimes masked by cyanosis), sweating and prolonged expiration are the worrying features, and if these are present the patient will certainly feel ' poorly' after the nitrous oxide administration. The degree of anoxia necessarily incurred in such patients may be followed by gross irregularities of respiration due either to mechanical obstruction or spasm of respiration. In obstruction caused by a combination of the patient's tongue, the throat pack and the dental surgeon's fingers, the ineffective movements of respiration continue although the patient has no air entry : in respiratory spasm the chest movements stop abruptly, and the chest is held rigidly in the position of inspiration. In either condition it is imperative to get the dental surgeon's fingers and the throat pack out of the mouth, and pull the tongue forward. The tongue may be hooked forward without damage with the first and second fingers of one hand, while the thumb of the other hand maintains the prop in position and prevents the closure of the mouth. The early rerognition and interference in such cases usually renders artificial respiration unnecessary.

For the patient who fights (or gives a history of fighting) as consciousness is lost with nitrous oxide, some adjuvant anaesthetic may be added. The older generation of dental anaesthetists slipped a sponge soaked in ether into the mouth: ethyl chloride or divinyl ether has been added by spraying into the bag or on a mouth pad, and in more recent times the vapour of trichlorethylene or a trickle of cyclopropane has been used. In hospital practice where the anaesthetic machine need not be portable, divinyl ether from a Harris' dripper ${ }^{3}$ or 'Trilene' from a Marrett's bottle ${ }^{4}$ work well : ethyl chloride and cyclopropane require much experience if the dose given to a fighting patient is not to be dangerously misjudged. As it is difficult to have these adjuvant vapours and gases available on a simple portable machine, in those cases which by previous trial or history are known to fight under nitrous oxide an intravenous anaesthetic is used as a supplement.

A second difficult type is the patient who will not tolerate a nose-piece sufficiently long to lose consciousness. Such patients begin to shake their heads before there is time for the nitrous oxide to have any effect, and end up by hooking their thumbs under the tubing of the nose-piece and pulling till it resembles a catapult. These cases may either be given a moderate dose of a sedative by mouth to produce a care-free state when inhalation anaesthesia will be tolerated, or a change is made to an induction with an intravenous barbiturate. The sedative used is 'Nembutal ' in doses from $I \frac{1}{2}$ to 3 grains, depending on the build and degree of nervousness of the patient. After the dose has been given the patient is asked to read in the waiting-room for an hour. Contrary to expectations such a period of waiting does not necessarily make them more nervous, and the writer has given nasal nitrous oxide with ease to a man who refused to tolerate a nose-piece after three attempts without sedation. Normally such patients are easier handled if given a minimal dose of an intravenous barbiturate to produce loss of consciousness, and nitrous oxide added as the subsequent anaesthetic.

When using an intravenous anaesthetic for a patient in the dental chair he should be seated as upright as possible to avoid the possible irritation of the throat by saliva trickling back during the slow induction. To allow the patient to answer when questioned as to freedom from pain or discomfort, the dental prop is not inserted until after the start of the injection. The dental surgeon is asked to place it in position before consciousness is lost, for the small dose given is usually insufficient to produce relaxation of the masseter muscles. The prop should be maintained in position by the dental surgeon to prevent it from falling out if the patient yawns. The injection is stopped at the point of the loss of the eye-lash reflex : from 0.25 to slightly more than 0.5 gram of thipoentone may be required.

A throat pack is inserted, and anaesthesia is continued with"nasal nitrous oxide and oxygen.

Apart from the intrinsic difficulty of judging the dose of thiopentone the following disadvantages of the technique must be remembered. 
(I) The uncommon but ever-present possibility of laryngeal spasm. The irritation of saliva during the induction or a trace of blood past the throatpack during maintenance is enough to produce this unpleasant complication. At the earliest sign of the onset of spasm the jaw is pushed well forward, and oxygen under pressure is offered to the patient through the nose-piece and mouth cover to minimize the increasing anoxia.

(2) Recovery is slow, and a patient cannot usually walk from the dental chair in less than 30 minutes after the start of the injection, or leave the premises for a further half an hour.

(3) The occasional restlessnes during the recovery, amounting at times almost to mania, demands constant supervision. The supervision does not end until the patient is leaving the surgery to be taken home by a responsible escort. The writer has been obliged not only to take an unaccompanied patient home, but also to drive and garage his car for him.

In patients with known heart disease such as recent coronary thrombosis, auricular fibrillation or a congenital heart lesion, nitrous oxide anaesthesia should not be used unless the anaesthetist can satisfy himself that the short period when the patient is exposed to diminished oxygen intake is not dangerous. The writer prefers to treat such patients in bed in their homes or in an operating theatre. An intravenous anaesthetic has the advantage of freedom from the possibility of a struggle during the induction, and nasal oxygen is given throughout the extractions.

For those patients suffering from lung diseases such as chronic bronchiectasis which interfere with the exchange of gases through the alveolar wall or of pulmonary tuberculosis where the increased depth of respiration associated with nitrous oxide anaesthesia may be undesirable, intravenous thiopentone may be used. Care should be taken that nothing irritates the pharynx and produces a bout of coughing, for the expelled mucus on a sensitive glottic opening may be followed by a severe laryngeal spasm.

Diabetics tolerate nitrous oxide and oxygen well, but the extractions should be timed to avoid missing a meal. A severe diabetic on large doses of insulin was allowed to rest on a comfortable couch after nasal nitrous oxide anaesthesia and fell asleep just before lunch. The writer was recalled several hours later to find a patient with slurred speech, in-coordinated movements and disorientated in space and time. The hypoglycaemia was corrected at the expense of part of the secretary's sugar ration, and the patient was normal within twenty minutes !

\section{Children}

A grave responsibility rests on the anaesthetist who first renders a child unconscious : the manner in which it is done may make or mar the small patient's relations with the dental surgeon and colour his outlook on anaesthetics for life. It is the skill of the anaesthetist with the agent he selects rather than any intrinsic merit of a particular drug, vapour or gas that produces good results. Thus Sington ${ }^{5}$ using ethyl chloride, Goldman divinyl ether ${ }^{6}$, Pinson cyclopropane ${ }^{7}$ and Galley trichlorethylene ${ }^{8}$ have shown how success may be obtained with differing anaesthetics.

When using nitrous oxide and oxygen in young children whose vital capacity is small, the narrow margin which divides too light an anaesthetic with associated cries and voluntary movement from partial asphyxia with cyanosis and jactatation often makes tranquil anaesthesia difficult to maintain. In spite of this drawback, many dental surgeons prefer their small patients to be given nitrous oxide and oxygen with the possibility of noise or movements because of the advantage of almost complete absence of after-effects. Considerable skill is required if any little incident such as slipping of the prop during the induction is not to lead to a series of troublesome results such as closure of the mouth, obstruction by the tongue, jactatations and opisthotonus. Under ethyl chloride, 'Trilene' or 'Vinesthene' anaesthesia, the level changes less rapidly, and the anaesthetist has leisure to replace the prop, insert a Mason's gag or adjust the position of the head.

The Oxford Inhaler ${ }^{9}$ is a useful apparatus for a ' one-shot' method in a small child of 5 or less. While the dose will vary with the build of the child and the number of teeth to be extracted, satisfactory anaesthesia will usually be obtained with 3 cc. of ethyl chloride, a 3 cc. ampoule of 'Vinesthene' or I.5 cc. of 'Trilene.' The disadvantages of the method is the necessity to present a bag in front of the child, the smell of the drug and the rubber of the bag, combined with the sense of suffocation induced by a full face-mask.

In the uncommon cases of the extraction of teeth in children of 3 years and under it is a help if the patient is seated on the mother's or nurse's lap with the head supported in the crook of the adult's elbow rather than attempt to prop him up in the chair with cushions. No attempt is made to insert a dental prop before the start of the induction, but before the stage of surgical anaesthesia is reached, the mouth is opened by separation of forefinger and thumb in the sulcus and a prop or Mason's gag rested in position.

For older children where the extractions may 
take time, nasal nitrous oxide is used, with the advantages of control of the duration of anaesthesia in contrast to 'one-shot' methods, the absence of a sensation of respiratory discomfort, and the negligible smell of the agent and apparatus, particularly if a metal nose-piece is used. In those cases where the immobility of the patient may be the determining factor between success and failure (such as the removal of 4 six-year-old molars) use is made of a strap to maintain the child in a good position in the chair. If introduced with a suitable aeroplane story about safety belts, which may be continued during the induction and recovery, the child will allow it to rest lightly over the thighs ; it is tightened just after the loss of consciousness.

For the un-cooperative child who is considered big enough to be given nitrous oxide yet cannot be persuaded even to sit in the chair, a satisfactory result may be obtained with pre-operative sedation. The child is brought to the waiting room one hour before the time of the extraction and is given 'Nembutal' by mouth. The dose varies with the size and build of the child : $1 \frac{1}{2}$ to 2 grains is about the average. The obvious criticism that the child will become more and more apprehensive during the long wait is not borne out in practice, and the writer has seen the previously 'impossible' patient led gently to the chair in a care-free state, and submit willingly to the insertion of a prop and the presentation of a nose-piece. The recovery is uneventful, and the child may be taken home immediately afterwards.

'Nembutal' occasionally causes restlessness and excitement almost approaching delirium, but the method is sufficiently valuable to disregard this uncommon drawback.

\section{REFERENGES}

I. MACINTOSH, R. R., and BANNISTER, F. B., ' Essentials of General Anaesthesia,' 4th Edition, 195.

2. Ibid, 205.

3. HARRIS, T. A. B. (1938), Brit. Med. Four., May 14, 1054.

4. MARRETT, H. R. (1942), Brit. Med. Four., May 23, 643.

5. SINGTON, H. (1930), Brit. Med. Four., Feb. I, 217.

6. GOLDMAN, V. (1936), Brit. Med. Four., July 18, 122.

7. PINSON, K. B. (1944), Brit. Med. Four., April 29, 588.

8. GALLEY, A. H. (1945), Lancet, Nov. 10, 597.

9. BOSTON, F. K., and SALT, R. (1940), Lancet, Nov. 16, 623.

\title{
BOOKS RECEIVED
}

\author{
The Editorial Board acknowledge with thanks the \\ receipt of the following volumes. A selection from \\ these will be made for review.
}

'Malignant Disease and its Treatment by Radium.' Volume I. By Sir Stanford Cade, K.B.E., C.B., F.R.C.S., M.R.C.P. 2nd Edition. John Wright \& Sons, Ltd. (Pp. xii $+384 . \quad$ I6I illustrations. 52s. 6d.) 1948.

'The Modern Management of Gastric and Duodenal Ulcer.' Edited by F. Croxon Deller, M.D., M.R.C.P. E. \& S. Livingstone Ltd. (Pp. 208. 57 illustrations. 20s.) I948.

' Emergencies in Medical Practice.' Edited by C. Allan Birch, M.D., F.R.C.P. E. \& S. Livingstone, Ltd. (Pp. xi +468 . I I 3 illustrations, eight in colour. 25s.) 1948 .
'The Mechanism of Abdominal Pain.' By V. J. Kinsella, M.B., Ch.M.(Syd.), F.R.C.S., F.R.A.C.S. Australasian Medical Publishing Company Ltd., Sydney. (Pp. xi + 230. Price 32s. 6d.) 1948.

“ "Elective Alimentary Rest" and the Elimination of So-called " Paralytic Ileus " after Abdominal Pain.' By V. J. Kinsella, M.B., Ch.M.(Syd.), F.R.C.S., F.R.A.C.S. Australasian Medical Publishing Company Ltd., Sydney (Pp. 35. 3s.) 1948.

'Disorders of Sex and Reproduction.' By A. P. Pillay, O.B.E., M.B., B.S. (H. K. Lewis \& Co., Ltd. (Pp. xiv + 300. I8s.) 1948 . 